\title{
Diversity of Endophytic Actinomycetes Producing Indole-3- Acetic Acid and In vitro Evaluation of Plant Growth-promoting Activity on Brassica oleracea $\mathbf{L}$.
}

\author{
Alimuddin Ali ${ }^{1 *}$, Nani Kurnia ${ }^{1}$, Andi Asrini Nurani Ulfah ${ }^{1}$, Putri Damayanti ${ }^{1}$, \\ Herlina Rante ${ }^{2}$ and Oslan Jumadi ${ }^{1}$
}

${ }^{1}$ Department of Biology, Universitas Negeri Makassar, Makassar 90222, Indonesia

${ }^{2}$ Department of Pharmacy, Universitas Hasanuddin, Makassar 90245, Indonesia

\begin{abstract}
The evaluation of endophytic actinomycetes diversity, growth-promoting strain effects on cauliflower seeds germination, and in vitro organogenesis are the objectives in this study. Moreover, 15 strains from 125 isolates were determined to produce indole-3acetic acid (IAA), where majority was obtained from roots $(66.67 \%)$, followed by from branches (26.67\%) and leaves (6.67\%). Specifically, Jatropha sp. is a plant species with the most endophytic actinomycetes content compared to others. In addition, all endophytic Streptomyces strains were screened based on IAA production ability in vitro on yeast extract-malt extract broth (YMG) broth medium. The results showed the tendency for one strain with code Streptomyces sp. KMR-1E to generate a maximum IAA isolate from Cinnamomun sp. plant. Furthermore, the molecular taxonomy and phylogenetic analysis were recreated from $16 \mathrm{~S}$ rRNA

ARTICLE INFO

\section{Article history:}

Received: 3 November 2020

Accepted: 11 March 2021

Published: 28 May 2021

DOI: https://doi.org/10.47836/pjtas.44.2.02

E-mail addresses:

muddin_69@unm.ac.id (Alimuddin Ali)

nanikurnia@unm.ac.id (Nani Kurnia)

asrininuraniulfah@gmail.com (Andi Asrini Nurani Ulfah)

puthedamayantii@gmail.com (Putri Damayanti)

herlinarante@unhas.ac.id (Herlina Rante)

oslanj@unm.ac.id (Oslan Jumadi)

*Corresponding author

gene sequences, which attributed the KMR$1 \mathrm{E}$ to genus Streptomyces. Meanwhile, plant growth promotion was evaluated under in vitro condition. This exposed the individual ability to enhance the shoot and root length of cauliflowers. The untreated cultures with a strain free agar block was used as control.

Keywords: Brassica oleracea L., endophytic actinomycetes, indole-3-acetic acid, plant growth promoter
\end{abstract}




\section{INTRODUCTION}

Actinomycetes symbolize a group of microbes instrumental in the performance of various beneficial functions, including antimicrobial actions, organic matter fragmentation, alongside mineral solubilization. Also, these bacteria are recognized as producers of plant growth modulators, and have found use in agriculture (Ilic et al., 2007; Suzuki et al., 2000). These organisms are recognized as intrinsic growth regulators, phytohormone synthesizers, as well as groundbreaking resources in plant diseases management (Zhao et al., 2018).

In previous decades, several genera, particularly the endophytic Actinobacteria were separated from the surfacesterilized roots of several plant types. These endophytes, in detail, are bacteria or fungi understood to establish habitats in intracellular, and often intercellular spaces of healthy plant tissue, devoid of the initiation of evident disease symptoms (Maela \& Serepa-Dlamini, 2019). Subsequently, the advantageous protection of these organisms from the competitive and demanding soil environment exhibits positive effects on the hosts (Shutsrirung et al., 2014). Moreover, some of the microbe's genetic properties are also shared with the molecular machinery required for plant-specific compound synthesis (Jasim et al., 2014). Also, the existence of endophytic Actinobacteria in the basal organs of healthy crops, including sorghum (de Araújo et al., 2000), banana (Cao et al., 2004), rice (Debananda et al., 2009), as well as the passion fruit (Ali et al., 2017) have been revealed in numerous research articles. Endophytic microbes are worthy of note as growth inducers in various stages of a plant's lifespan including during biological nitrogen fixation (BNF), to facilitate the reduction of dinitrogen $\left(\mathrm{N}_{2}\right)$ to ammonia $\left(\mathrm{NH}_{3}\right)$, the mobilization of insoluble phosphates, in conjunction with growth enhancement potentials (da Costa et al., 2014; Sharma et al., 2013).

Furthermore, Streptomyces olivaceoviridis, Streptomyces rimosus, and Streptomyces viridis were implicated as members of the unique Streptomyces genera of endophytic plants assumed to play a role in IAA synthesis, and subsequently advance plant expansion by enhanced propagation of seeds, alongside root, and shoot extension (El-Tarabily, 2008; Khamna et al., 2010; Tokala et al., 2002). However, data on the yield generated by the Cinnamomum sp. and the resultant application in growth promotion is deficient.

Additionally, the cauliflower (Brassica oleracea L.) has been cultivated constantly in South Sulawesi for over five decades and is considered an important commercial vegetable. However, increased production indicates a higher use of agricultural chemicals, including manure and insecticides. These chemical applications for extended periods threaten local communities, as well as the environment. Therefore, government policies aim to practice organic agriculture through reduced agrochemical use, and a tactic used involved the application of beneficial microorganisms as inoculants for biocontrol or biofertilizer (Berg, 2009; Malus'a et al., 2012). 
Also, several benefits to the bacteria are enhanced through the diversion of host physiological processes by the synthesis of auxins. Moreover, present records demonstrate the strenuous effects of IAA on seed germination, as well as the potential for induction of Brassica oleracea L. explant organogenesis by this compound in actinomycetes.

\section{MATERIALS AND METHODS}

\section{Sample Collection}

All the specimens (roots, branches, and leaves) were collected from a variety plant species in South Sulawesi, Indonesia. Subsequently, the samples were chopped up using a cutter blade, reserved in sterilized plastic bags labelled according to species as well as site sampling, and subsequently returned to the laboratory where bacteria segregation was performed within 48 hours.

\section{Isolation and Selection of Endophytic Actinomycetes}

Dirt, debris, as well as surface agents were eliminated from the plant tissues samples by the use of running water. Then, the bacteria were isolated by the reduction of the plant parts into smaller portions $\left(0.2 \times 4 \mathrm{~cm}^{2}\right)$, and consequently sterilized externally through serial treatment with $70 \%(\mathrm{v} / \mathrm{v})$ ethanol for 10 minutes. Subsequently, 1\% sodium hypochlorite was added for 5 minutes then rinsed four times in sterilized water.

The air-dried specimen was further excised into approximate sizes of $2 \times 3 \mathrm{~mm}$ and transplanted onto Starch Casein (SC) agar enhanced with $100 \mu \mathrm{g} / \mathrm{mL}$ nystatin.
Moreover, bacteria colonies surrounded the plant tissue at $30^{\circ} \mathrm{C}$ after an incubation period of 2-3 weeks. These were therefore isolated by the transfer of the clusters onto fresh SC agar plates until purity was indicated by an individual colony. The unadulterated culture was then placed in a $15 \%$ sterile glycerol suspension at $-80^{\circ} \mathrm{C}$ to facilitate preservation through an extended period.

\section{Authentication of the Surface Sterilization Protocol}

The test procedures were validated by the inoculation of $0.1 \mathrm{~mL}$ aliquots of the resultant specimen suspension on SC agar. Subsequently, the samples were incubated at $30^{\circ} \mathrm{C}$ for 5 days, before microbial growth analysis. The absence of bacterial proliferation confirmed the protocol as effective.

\section{Evaluation for Indole-3-acetic Acid (IAA) Production by Endophytic Isolates}

The amount of synthesized hormones was estimated in correspondence with the technique proposed by Bano and Musarrat (2003). This was implemented by the cultivation of the agar block $(6 \mathrm{~mm}$ in diameter) of the bacterial colonies on yeast extract-malt extract broth (YMG) $(\mathrm{g} / \mathrm{L})$ (made up of yeast extract $16 \mathrm{~g}$, malt extract $10 \mathrm{~g}$, and glucose $4 \mathrm{~g}$ ), alongside a final incubation at $35{ }^{\circ} \mathrm{C}$ for a period of seven days. Then, the culture was transferred into $5 \mathrm{~mL}$ YMG broth inclusive of $2 \mathrm{mg} / \mathrm{mL}$ L-tryptophan, before the final incubation 
and concurrent agitation at $35^{\circ} \mathrm{C}$ and 125 rpm for 7 days, respectively.

The cells were consequently harvested by using a centrifuge at $20,328 \times \mathrm{g}$ for 15 minutes, and $1 \mathrm{~mL}$ of the upper layer of the product combined with $2 \mathrm{~mL}$ of Salkowski reagent $\left(1 \mathrm{~mL}\right.$ of $0.5 \mathrm{M} \mathrm{FeCl}_{3}$, in $49 \mathrm{~mL}$ of $35 \% \mathrm{w} / \mathrm{v} \mathrm{HClO}_{4}$ ), with the resulting solution incubated at $30{ }^{\circ} \mathrm{C}$ for 25 minutes in an environment without light. Subsequently, conversion of the color to a pink hue was suggestive of a positive test. The optical density (OD) was then ascertained with the employment of a spectrophotometer with a wavelength of $535 \mathrm{~nm}$, and the resultant level of IAA produced appraised against the standard.

\section{Preliminary Phenotypic}

\section{Characterization of IAA Producing Strain}

A phenotypic characterization was performed on all strains producing endophytic IAA using the International Streptomyces Project (ISP) medium. Therefore, the morphological and cultural properties, including the spore mass color, existence of aerial hypha, diffusible pigments color, unique reverse colony color, as well as spore chain morphology were evaluated (Cao et al., 2004).

\section{Expulsion and Identification of IAA}

This detection process involved the use of isolates assumed to produce the highest IAA. The area above this culture was then obtained using a centrifuge at 20,328 x $g$ for 15 minutes after fermentation on YMG broth media supplemented with $2 \mathrm{mg} / \mathrm{mL}$ L-tryptophan at $35^{\circ} \mathrm{C}$ and $125 \mathrm{rpm}$ for 7 days. Also, IAA extraction was conducted based on the procedure from Ahmad et al. (2005). This required acidifying the culture supernatant to $\mathrm{pH} 2.5$ with $\mathrm{HCl}$, and the supernatant culture: ethyl acetate $(1: 2 \mathrm{v} / \mathrm{v})$ was subsequently adopted. The confirmation of isolates determined to produce this acid was conducted using thin layer chromatography (TLC) methods. This method was further executed with 25 $\mu \mathrm{L}$ ethyl acetate macerate stained on TLC plates (silica gel $\mathrm{GF}_{254}$, thickness $0.25 \mathrm{~mm}$, Merck, Germany) and developed using ethyl acetate: chloroform: formic acid (55:35:10 $\mathrm{v} / \mathrm{v}$ ) as the mobile phase. Furthermore, UV light $(254 \mathrm{~nm})$ was used to confirm the points with similar retention factor $\left(R_{f}\right)$ values as the original pure IAA chemical after Ehmann's reagent was sprayed on the LC plates (Vikram, 2011).

\section{Optimization of IAA Production Condition}

The IAA production process was improved by evaluating the impact of incubation period on the culture temperature and $\mathrm{pH}$ condition. Therefore, similar medium and conditions as described above were used to culture the isolate. Furthermore, the incubation period effect was examined over a 10-day period.

\section{Effect of Soaking on Seed Germination}

The cauliflower seeds were subjected to surface sterilization for 10 minutes, using $10 \%(\mathrm{w} / \mathrm{v}) \mathrm{NaOCl}$. This was followed by 
a thorough wash with sterile distillated water, and air drying, before soaking in the KMR-1E strain culture filtrate (grown in YMG broth medium broth amended with L-tryptophan $2 \mathrm{mg} / \mathrm{mL}$, incubated for 7 days at $30^{\circ} \mathrm{C}$ ). Furthermore, the authentic IAA (Merck) was immersed in the same sterile distillated water $(0.5 \mu \mathrm{g} / \mathrm{mL})$ and applied as the study control. Therefore, a tentative therapy was conducted over the agar block of KMR1 strain (grown on YMG agar medium modified L-tryptophan).

The seeds were then cultured on the water agar media $(5 \% \mathrm{w} / \mathrm{v})$ placed within a Petri dish (9 $\mathrm{cm}$ in diameter), and arranged vertically in the growth chamber, in an attempt to facilitate seed maturation with no restrictions. Subsequently, the extent of growth was evaluated after 10 days of germination, based on number of roots, fresh weight of plant, primary root, and shoot length.

\section{Assessment of Plant Growth Promotion in Cauliflower Tissue Culture Treated with Specific Endophytic Actinomycetes}

The KMR-1E strain growth promotion capacity was assessed in vitro in a bottle chamber $(6 \mathrm{~cm}$ in diameter and $20 \mathrm{~cm}$ height). This was followed by using tap water to wash the cauliflower stalk and remove particles as well as other agents. The representative cauliflower $(2 \times 2.5 \mathrm{~cm})$ obtained per explant was purified through 10 minutes of continuous submersion in $\mathrm{NaOCl} 10 \%$ (w/v) and consequently soaked in an autoclaved distilled water four times. Subsequently, the explants were finally air dried after cutting into thin blocks $(2 \times 10$ $\mathrm{mm}$ ) and placed without or with IAA on the basal MS medium. This vehicle had an adjusted $\mathrm{pH}$ of 5.8 prior to autoclaving. Meanwhile, the IAA stock solution was prepared with $100 \mathrm{~mL}$ purified water, and filtered with a $0.2 \mu \mathrm{m}$ sterile membrane filter.

The control (K0) sample encompasses the flowers branches of cauliflower explant yield cultivated on Murashige and Skoog (MS) primary medium with $1 \%$ sucrose. Also, different treatments, including the explant grown in this agent, and free strain YMG agar block medium modified L-tryptophan (NS) were evaluated, and consequently transferred at a ratio of 1 to 3 per explant. In addition, YMG medium agar block amended L-tryptophan with KMR1 strain (ST) was used in one of the experimental treatments, while the other involved genuine IAA (PC) altered to $0.15,0.2$, and $0.25 \mu \mathrm{g} / \mathrm{mL}$, respectively. Figure 1 shows the test reserved within the conditions of $24^{\circ} \mathrm{C}, 24 \mathrm{~h}$ light, and $60 \% \mathrm{~mm}$ for the cultivated plant part. Therefore, measurements were obtained all parameter data after a 3-week culture period. The three treatments were conducted using a completely randomized design.

\section{Molecular Identification of Selected Endophytic Actinomycetes by $16 \mathrm{~S}$ rDNA Sequence Analysis}

The selected KMR-1E strain cells were cultured in YMG for 4 days. Therefore, the DNA genome was prepared with minor modification, according to Badji 
et al. (2006). In addition, two primers were applied during the amplification of $16 \mathrm{~S}$ rDNA, including: $27 \mathrm{~F}$ 5'-AGAGTTTGATCCTGGCTCAG-3' and 1492R 5'-GGTTACCTTGTTACGACTT-3'. Also, through an Invitrogen ${ }^{\mathrm{TM}} \mathrm{Kit}$, polymerase chain reaction (PCR) was adopted for gene sequence amplification, and the final reaction mixture volume $(50 \mu \mathrm{L})$ comprised of $50 \mathrm{ng}$ template DNA; 10 mol primer concentration; PCR master mix containing Taq DNA polymerase, dNTPs, Tris-HCl, $\mathrm{MgCl}_{2}$ stabilizer; as well as tracking dye applied based on the manufacturer's instructions. The amplification process was conducted on a thermal cycler (Gene Cycler ${ }^{\mathrm{TM}}$, Bio-Rad) by exposing sample to an initial denaturation step for 5 minutes, with temperature set at 96 ${ }^{\circ} \mathrm{C}$. Subsequently, 30 amplification cycles of $95^{\circ} \mathrm{C}$ for 1.5 minutes, $55.5^{\circ} \mathrm{C}$ for 1 minute, $72^{\circ} \mathrm{C}$ for 5 minutes, and $72^{\circ} \mathrm{C}$ for 5 minutes was conducted. Therefore, electrophoresis was adopted for gene detection using 1.5\% $(w / v)$ agarose gels stained with ethidium bromide. In addition, using BLAST NCBI search (http://blast.ncbi.nlm.gov/), the $16 \mathrm{~S}$ rRNA gene sequence in KMR-1E variants was subjected to similarity analysis. Subsequently, an evolutionary tree was suggested based neighbor-joining (Saitou \& Nei, 1987), while phylogenetic analysis and multiple alignments involved the Clustal X program (Thompson et al., 1994). The tree topology was evaluated based on 1,000 replicates, and using the bootstrap analysis (Felsenstein, 1985).

\section{Statistical Analysis}

Data were subjected to ANOVA using SPSS software version 16.0 for Windows. Statistical differences between means were compared using least significant difference (LSD) test at $p=0.05$.

\section{RESULTS AND DISCUSSION}

\section{Diversity of the Endophytic Strain}

The various plant tissue possessed a total of 125 endophytic actinomycetes strains, and

\section{O : agar block without strain KMR-1 \\ - : agar block with strain KMR-1 \\ $\nabla$ : explant of cauliflower stalk}

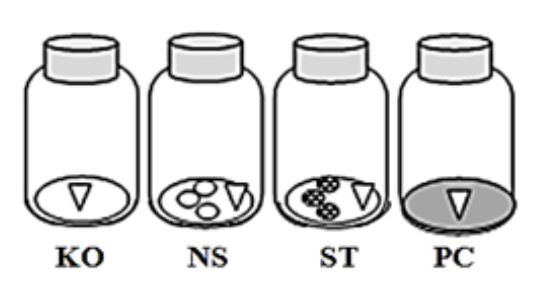

Figure 1. Schematic of in vitro evaluation of growth promoting substances produced by endophytic actinomycetes on cauliflower stalk plant growth promotion response 
15 were selected for further studies. Table 1 illustrates the negative bacteria growth on SC agar medium in the representative samples from every crop treated with the surface sterilization protocol. This proves the elimination process for this organism was effective using this method. Furthermore, from the isolates screened for endophytic plant, the highest and lowest number of strains were obtained from the roots and leaves where $\mathrm{n}=64.4 \%$ and $18.4 \%$, respectively. These were discovered to produce IAA. The majority of isolates were separated from roots $(66.67 \%)$, branches (26.67\%), and leaves (6.67\%). In addition, most of the bacteria were obtained from Jatropha sp. and the predominant plant had at least one isolate yield, therefore the organism is able to colonize different parts of various tissues.

The isolation of microbe in a culture medium is a simple method for assessing the bacterial communities (Andreote et al., 2009), although this is an underestimation in terms of diversity relating to the microbial populations. This is because bacterial identification is significantly influenced by the growth of selected specific culture medium. Also, microbial populations vary for different vegetation and species inhabit. The populations of microbes differ depending on the locations or climatic conditions even in similar plant species (Nair \& Padmavathy, 2014). Moreover, colony appearances, including substrate hyphae and spore mass color on ISP Medium No. 3 displayed the

Table 1

The occurrences of endophytic actinomycetes strain from different plant species

\begin{tabular}{lcccc}
\hline \multirow{2}{*}{ Plant species } & \multicolumn{2}{c}{ Plant tissue of endophytic strain sources } & $\begin{array}{c}\text { No. of } \\
\text { endophytic } \\
\text { strain }\end{array}$ \\
\cline { 2 - 4 } Cinnamomum sp. & Roots & Stem barks & Leaves & 14 \\
Piper sp. & $5(2)$ & 1 & 1 & 11 \\
Ficus & $14(1)$ & $2(1)$ & 4 & 23 \\
Hibiscus sp. & 6 & 4 & 5 & 9 \\
Areca sp. & $7(1)$ & $2(1)$ & 1 & 9 \\
Unidentified fern & $11(1)$ & 1 & 1 & 18 \\
Manihot sp. & $9(1)$ & 1 & 4 & 14 \\
Jatropha sp. & $17(3)$ & $7(2)$ & 4 & 27 \\
Total & $83(10)$ & $21(4)$ & $23(1)$ & 125 \\
Percentage & $64.4 \%$ & $16.8 \%$ & $18.4 \%$ & \\
& $(66.67 \%)$ & $(26.67 \%)$ & $(6.67 \%)$ & \\
\hline
\end{tabular}

Note. $*$ Value in brackets indicates the number of endophytic actinomycetes strain IAA producing 
isolates in form of two different groups. These included the Streptomyces-like strain distinguished by an abundant aerial mycelium with powdery spores and the non-Streptomyces variant marked by red, orange, and brown to black slimy colonies. The Streptomyces-like strain represented $66.67 \%$ of the endophytic species, majorly the $\mathrm{S}$ of spore chain type. According to Sardi et al. (1992), 499 endophytic actinomycetes were separated from various crops, with approximately $96 \%$ Streptomyces and $0.2 \%$ Streptosporangium. The non-Streptomyceslike strain was discovered to colonize roots in this study as noted earlier by Goudjal et al. (2013).

\section{Screening of IAA Production of Endophytic Strain}

The isolates screening for the presence of beneficial traits indicated 15 strains were discovered to be the producers of IAA. This acid generation has a high variability range of 17.65 to $86.94 \mu \mathrm{g}$ / $\mathrm{mL}$ for Streptomyces-like strain and a value of 21.41 to $68.12 \mu \mathrm{g} / \mathrm{mL}$ for nonStreptomyces-like strain. Furthermore, 8 plants of endophytic actinomycetes were discovered with the potential to generate this acid in the present study. Table 2 demonstrates the high production ability of two variants termed KMR-1E and KMR-11. This was the most significant amongst all other genera, with a value of $86.94 \mu \mathrm{g} / \mathrm{mL}$. Also, IAA was determined to be the main auxin in plants, due to the vital function possessed by this acid in the first processes of lateral and adventitious root formation and elongation (Idris et al., 2007). The presence of microorganism colonies in plant tissue has a vital role in vegetation. According to Shutsrirung et al. (2014), IAA produced by Streptomyces spp. was ranged between 1.05 to $60.95 \mu \mathrm{g} / \mathrm{mL}$ and 11 to $54 \mu \mathrm{g} / \mathrm{mL}$. This study discovered a high variation level in the auxin production by Streptomyces with the exception of Streptomyces viridis CMU-H009 at a value of $143.95 \mu \mathrm{g} / \mathrm{mL}$ (Khamna et al., 2010).

Table 2

Morphological characteristic and estimation of IAA production of endophytic Actinomycetes

\begin{tabular}{lccccc}
\hline Groups & Plant sources & $\begin{array}{c}\text { Diffusible } \\
\text { pigment }\end{array}$ & $\begin{array}{c}\text { Spore- } \\
\text { chain } \\
\text { type* }\end{array}$ & Group of genera & $\begin{array}{c}\text { Concentration of } \\
\text { IAA }(\mu \mathrm{g} / \mathrm{mL})\end{array}$ \\
\hline KMR-1E & Cinnamomum sp. & - & $\mathrm{F}$ & Streptomyces & $86.94 \pm 0.71$ \\
KMR-2 & Cinnamomum sp. & - & RF & Streptomyces & $38.00 \pm 0.67$ \\
KMR-4a & Piper $\mathrm{sp}$. & - & $\mathrm{S}$ & Streptomyces & $64.59 \pm 0.69$ \\
KMR-4b & Piper $\mathrm{sp}$. & - & $\mathrm{R}$ & Streptomyces & $86.29 \pm 0.79$ \\
KMR-11 & Ficus $\mathrm{sp}$. & Yellow & RA & Streptomyces & $86.92 \pm 0.77$ \\
KMR-12 & Hibiscus sp. & - & $\mathrm{RF}$ & Streptomyces & $65.18 \pm 0.42$ \\
KMR-15 & Areca $\mathrm{sp}$. & - & $\mathrm{S}$ & Streptomyces & $36.59 \pm 0.57$ \\
\hline
\end{tabular}


Table 2 (Continued)

\begin{tabular}{|c|c|c|c|c|c|}
\hline Groups & Plant sources & $\begin{array}{c}\text { Diffusible } \\
\text { pigment }\end{array}$ & $\begin{array}{l}\text { Spore- } \\
\text { chain } \\
\text { type* }\end{array}$ & $\begin{array}{l}\text { Group of } \\
\text { genera }\end{array}$ & $\begin{array}{c}\text { Concentration of } \\
\text { IAA }(\mu \mathrm{g} / \mathrm{mL})\end{array}$ \\
\hline KMR-22 & $\begin{array}{l}\text { Unidentified } \\
\text { fern }\end{array}$ & - & - & $\begin{array}{c}\text { Non- } \\
\text { Streptomyces }\end{array}$ & $21.41 \pm 0.31$ \\
\hline KMR-23 & Manihot sp. & Brown & - & $\begin{array}{c}\text { Non- } \\
\text { Streptomyces }\end{array}$ & $68.12 \pm 0.78$ \\
\hline KMR-26a & Jatropha sp. & - & $\mathrm{S}$ & Streptomyces & $17.65 \pm 0.34$ \\
\hline KMR-26b & Jatropha sp. & - & S & Streptomyces & $19.06 \pm 0.21$ \\
\hline KMR- $26 b_{2}$ & Jatropha sp. & - & - & $\begin{array}{c}\text { Non- } \\
\text { Streptomyces }\end{array}$ & $61.06 \pm 0.59$ \\
\hline KMR- 26c & Jatropha sp. & - & S & Streptomyces & $44.00 \pm 0.62$ \\
\hline KMR- 26d & Jatropha sp. & - & - & $\begin{array}{c}\text { Non- } \\
\text { Streptomyces }\end{array}$ & $27.53 \pm 0.33$ \\
\hline KMR-26e & Jatropha sp. & - & - & $\begin{array}{c}\text { Non- } \\
\text { Streptomyces }\end{array}$ & $66.94 \pm 0.58$ \\
\hline
\end{tabular}

Note. ${ }^{*} \mathrm{RA}=$ Rectiaculiaperti; $\mathrm{RF}=$ Rectiflexibiles; $\mathrm{S}=$ Spiral. IAA was estimated 7 days after the endophytic actinomycete growth in YMG broth medium supplemented $2 \mathrm{mg} / \mathrm{mL}$ of L-tryptophan with absorbance at $540 \mathrm{~nm}$

\section{Detection and Optimization of IAA Production by KMR1 Strain}

The detection and comparison of IAAproducing strain with standard auxins was performed using TLC chromatograms. Furthermore, pink color spot of ethyl acetate extract at $\mathrm{R}_{\mathrm{f}} 0.6$, correspond to the authentic compound, therefore IAAproducing organism is a potential source for the chemical. Meanwhile, this technique is important for the qualitative or semiqualitative determination detection of the acid. This method assured the hormone presence in the unrefined top layers of these samples of bacterial cultures. The Salkowski reagent reacted with the acid but not with L-tryptophan and Na-acetyl-L-tryptophan (Vaghasiat et al., 2011). Figure 2 presents the effects of incubation periods toward the hormone production of KMR-1E strain. The results showed this process commenced after 24 hours, and gradually increased after 7 days of incubation with a reduction on the 8th day. This impact was studied to acquire knowledge on the optimal culture condition for the highest producer termed KMR-1E. Also, adjustments were made to the culture media $\mathrm{pH}$, temperature, and L-tryptophan concentration with reference to previous studies. The maximum yield was obtained after a 7-day incubation period, as shown in the results time exponent. This reduction occurs as a result of oxidase and peroxidase activity as indicated in the Rhizobium sp. from Cajanus cajan (Datta \& Basu, 2000). This is congruent with the agreement in a research on Streptomyces sp. PT2 (Goudjal et al., 2013). 


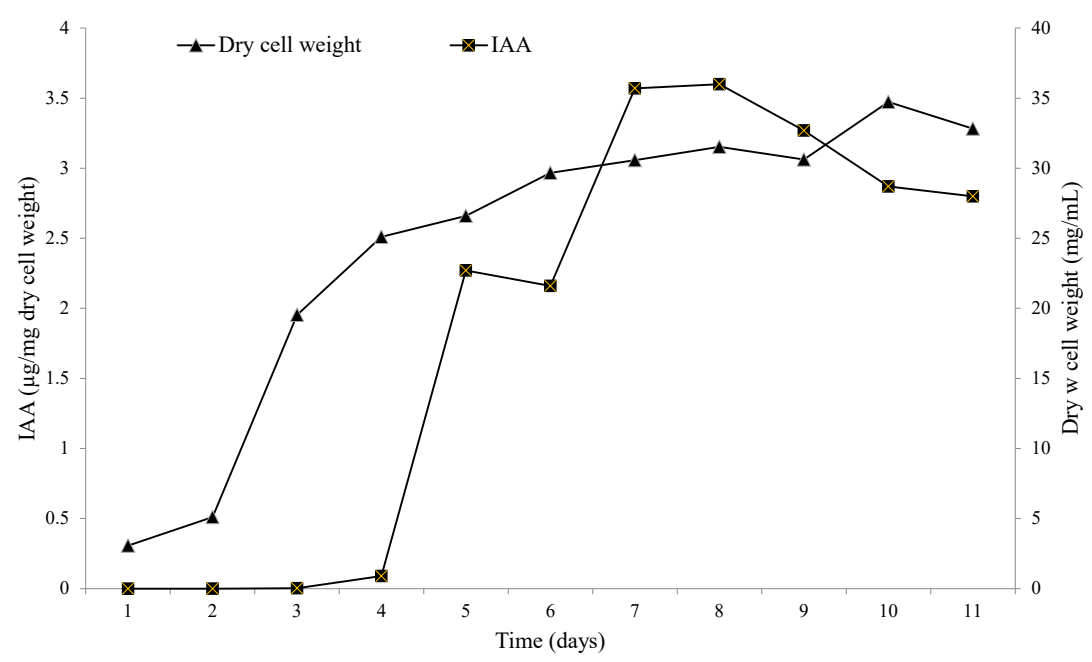

Figure 2. Time course of indole-3-acetic acid (IAA) production by strain Streptomyces KMR-1E on YMG broth (amended L-tryptophan $2 \mathrm{mg} / \mathrm{mL} ; \mathrm{pH} 7 \pm .05$ ) at temperature $35^{\circ} \mathrm{C}$ for different incubation periods. In addition, each value was determined as the mean of 3 replicates

\section{Effect of Presoaking Periods and IAA Treatments on Seed Germination and Root Elongation}

Table 3 shows a significant improvement in the germination of inoculated cauliflower seeds induced by the growth modulator of the KMR-1E strain against an uninoculated control, examined over 10 days according to the test conditions. Furthermore, an agar block of medium containing the strain alongside IAA standard exhibited greater limb lengths and biomass, unlike the pre-soaked seed untreated with the crude supernatant of the KMR-1E strain (control). Meanwhile, important variations were not noted between specimens processed with IAA and an agar block of YMG without L-tryptophan, in terms of percentage root and shoot lengths, higher biomass, as well as the number of adventitious roots.
The samples impregnated with IAA, YMG agar slab alongside the strain modified with L-tryptophan demonstrated substantial distinctions when assessed against the control, as well as the aforementioned presoaked seed sample. Therefore, the seed treatment was revealed to have affected the root and shoot expansion as shown in Figure 3. Subsequently, the ensuing outcome proved the immersion of the seeds for 5 hours in standard IAA and agar block YMG medium amended with L-tryptophan as the major responsive assay. This outcome approved a former research performed with sugar beets (Shi et al., 2009), where considerable growth of the seedlings was observed. Several researches corroborated the ability of endophytic actinomycetes to synthesize IAA, and consequently improve plant growth by intensifying 
plant cultivation. The improvement of tomato seeds with the culture top layer containing the unadulterated IAA was also observed. Also, previous documentation described the advanced seed germination and root extension produced in Ochetophilia trinervis by IAA-generating endophytic actinomycetes (Solans et al., 2011). Also, the Streptomyces sp. isolated from Centella asiatica possessed the potential to enhance the earlier stated characteristics (Dochhil et al., 2013).

Table 3

Effects of endophytic actinomycetes strain on the growth of cauliflower seedling

\begin{tabular}{|c|c|c|c|c|}
\hline Treatment & $\begin{array}{l}\text { Fresh } \\
\text { primary root } \\
\text { length }(\mathrm{cm})^{*}\end{array}$ & $\begin{array}{l}\text { Fresh shoot } \\
\text { length }(\mathrm{cm})^{*}\end{array}$ & $\begin{array}{l}\text { No of } \\
\text { adventive } \\
\text { roots }\end{array}$ & $\begin{array}{l}\text { Fresh plant } \\
\text { biomass } \\
\text { weight }(\mathrm{g})^{*}\end{array}$ \\
\hline (A) Control & $2.025^{\mathrm{a}}$ & $2.550^{\mathrm{a}}$ & $2.750^{\mathrm{a}}$ & $0.046^{\mathrm{a}}$ \\
\hline $\begin{array}{l}\text { (B) YMG broth medium with } \\
\text { KMR-1E strain and } \\
\text { amended L-tryptophan }\end{array}$ & $6.950^{\mathrm{b}}$ & $4.700^{\mathrm{b}}$ & $5.250^{\mathrm{b}}$ & $0.061^{\mathrm{ab}}$ \\
\hline $\begin{array}{l}\text { (C) YMG solid medium with } \\
\text { KMR-1E strain and } \\
\text { supplied L-tryptophan }\end{array}$ & $7.720^{\mathrm{b}}$ & $4.950^{\mathrm{ab}}$ & $5.750^{\mathrm{b}}$ & $0.079^{\mathrm{b}}$ \\
\hline (D) IAA authentic standard & $7.550^{\mathrm{b}}$ & $4.900^{\mathrm{ab}}$ & $6.100^{\mathrm{b}}$ & $0.073^{\mathrm{b}}$ \\
\hline
\end{tabular}

Note. *It was measured after 10 days of seedling. Means followed by the same lowercase letter within the same column were not significantly different based on LSD test $(p=0.05)$. There were 3 replications per treatment (4 plants per replication)

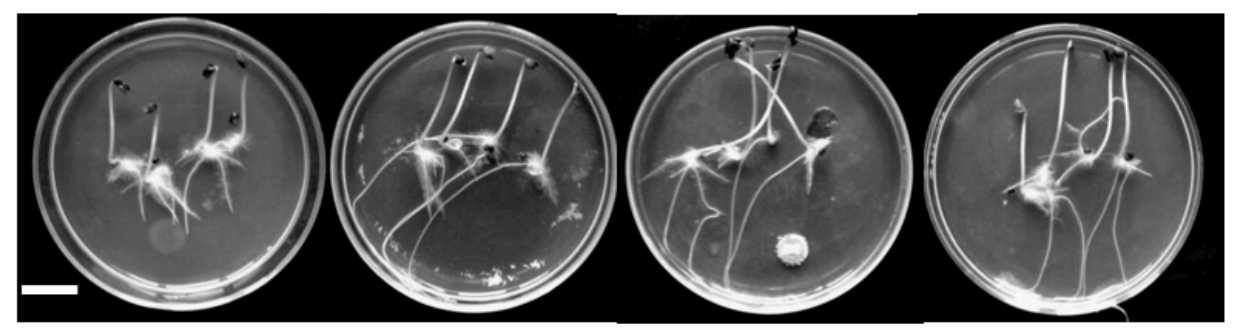

A

B

C

$\mathrm{D}$

Figure 3. Early development of cauliflower (Brassica oleracea L.) seedling. These seeds were surface sterilized and placed on water agar $(5 \%)$ for germination at $25^{\circ} \mathrm{C}$ in a plant growth chamber for 10 days. The images showed the representative photographs of the cauliflower seedling, and each scale bar represents $2 \mathrm{~cm}$ Note.

A. Brassica seeds were applied with sterile aquadest as seed soaking treatments

B. Brassica seeds were soaked with YMG broth medium with KMR-1E strain

C. Media were applied as block agar YMG medium with KMR-1E strain placed on surface of growth media

D. Brassica seeds were soaked with IAA pure chemical $(0.5 \mu \mathrm{g} / \mathrm{mL})$ 


\section{The Organogenesis of the Cauliflower} Explants through In vitro Procedures

The stalk explants with dimensions of 2 $\times 2.5 \mathrm{~cm}$ were transferred to a basal MS medium, and the length of the plant limbs, alongside the induction of adventitious roots were observed across all the samples after fourteen days of culture. However, the optimal response was observed for the cultures comprising of the strain adjusted with L-tryptophan and IAA, where sizeable variations in branches and roots sizes, as well as the absence of alterations in the number of leaf regeneration, in contrast to the control and the sample without strain ( $p$ $<0.05$ ), were displayed. Therefore, species producing IAA from media enriched with L-tryptophan displayed greater potentials for shoots and adventitious roots height extension, as well as biomass weight enhancement in contrast with the control (Figures 4-5), as indicated by the results. Consequently, the potential of IAAproducing endophytic actinomycetes to induce the organs of $B$. oleracea L. explants was demonstrated. Despite the tissue culture on MS basal medium and treatment with YMG agar block, the media provided insignificant responses compared with the control. The medium treated with strain and IAA exhibited better outcomes of explant regrowth. Furthermore, cauliflower regeneration was influenced by several factors, including the media components (Kaur et al., 2006; Ovesna et al., 1993), growth regulators (Hoque, 2010), culture conditions as well as explant types (Kerlley et al., 2012). In general, the addition of auxin and bacterial metabolites were observed to appreciably improve organogenesis, especially of the plant limbs and roots. Also, the utilization of actinobacterial cultures for inoculation also significantly improved growth and development, specifically of the plant limbs, and biomass (Jog et al., 2014).

This experiment has also demonstrated the comparable in vitro shoot and root induction potential of IAA-producing endophytic actinomycetes to the commercially available phytohormone. The results indicate the inability for minimum concentrations in YMG medium agar block to demonstrate significant organogenesis response in contrast with IAA standards for all parameter except number of roots.

\section{Characteristics of Streptomyces sp. KMR-1E Strain}

Figure 6 shows the reconstruction of molecular taxonomy and phylogenetic analysis based on 16S rRNA gene sequences. This phenomenon prompted the strain designation to genus Streptomyces. KMR$1 \mathrm{E}$ strain shared $97 \%$ similarity with Streptomyces tendae NBRC 12822, and thus assigned as a closely related species to Streptomyces albogriseolus DSM 40003 and Streptomyces violaceolatus NBRC 13101. In addition, there was a spiral chain spore formation with KMR-1E strain. Meanwhile, the $S$. tendae retinaculiaperti or spiral on salts starch agar. S. tendae demonstrated a massive gray aerial color on yeast lactose, salts-starch agar, and oatmeal, while KMR$1 \mathrm{E}$ strain showed a pure white coloration, as observed in Table 4. The reverse side 
of a colony is yellow, while the KMR-1E the $S$. tendae showed no growth signal on strain showed a sand yellow coloration. raffinose (Whitman et al., 2012).

This particularly utilized glucose, raffinose, inositol, sucrose, and D-mannitol while

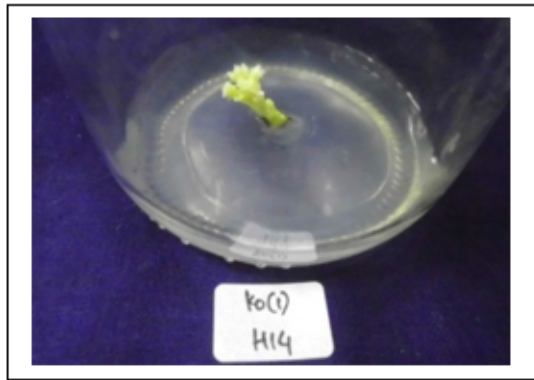

A

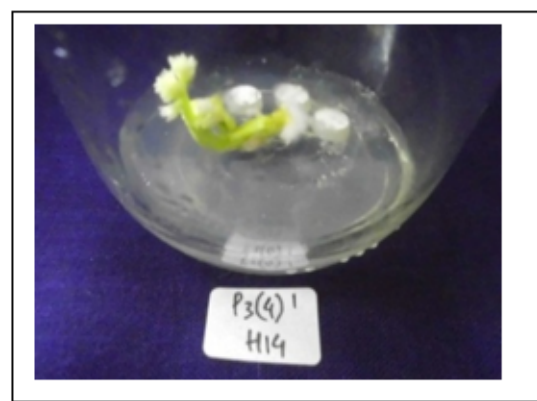

$\mathrm{C}$

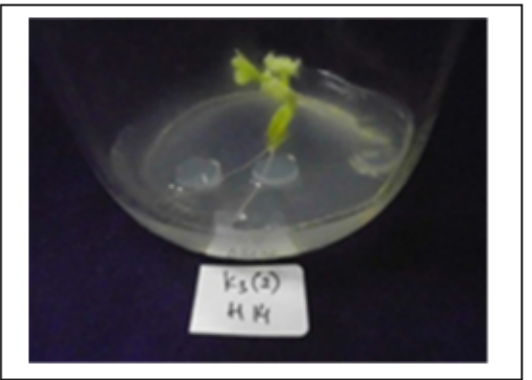

B

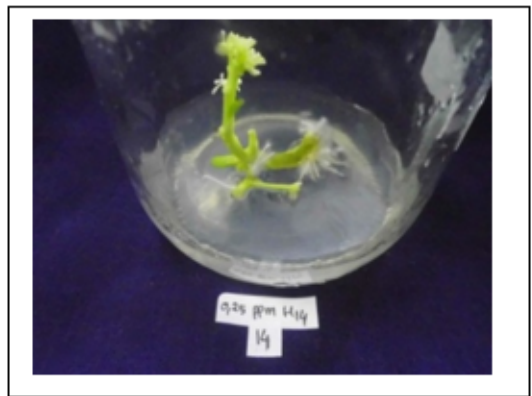

$\mathrm{D}$

Figure 4. Effect of strain KMR-1E agar block on the organogenesis of cauliflower stalk after a 14-day culture period. The flower branches were cultured on Murashige and Skoog (MS) basal medium supplemented with $1 \%$ sucrose and consequently used as (A) control (K0) then MS basal medium alongside agar block of YMG medium, (B) without strain and amended L-tryptophan (NS), (C) characterized by amended L-tryptophan with KMR-1E strain (ST), (D) treated by authentic IAA (PC)

Table 4

Cultural characteristics of KMR-1E strain on different culture mediums

\begin{tabular}{lccc}
\hline Agar medium & Aerial mycelium & Substrate mycelium & Growth \\
\hline ISP1 & Pure white & Brown beige & Good growth \\
ISP2 & Pure white & Sand yellow & Moderate growth \\
ISP3 & No growth & No growth & No growth \\
ISP4 & Ochre brown & Orange, brown & Good growth \\
ISP5 & Cream & Cream & Moderate growth \\
ISP6 & Pure white & Sand yellow & Good growth \\
\hline
\end{tabular}




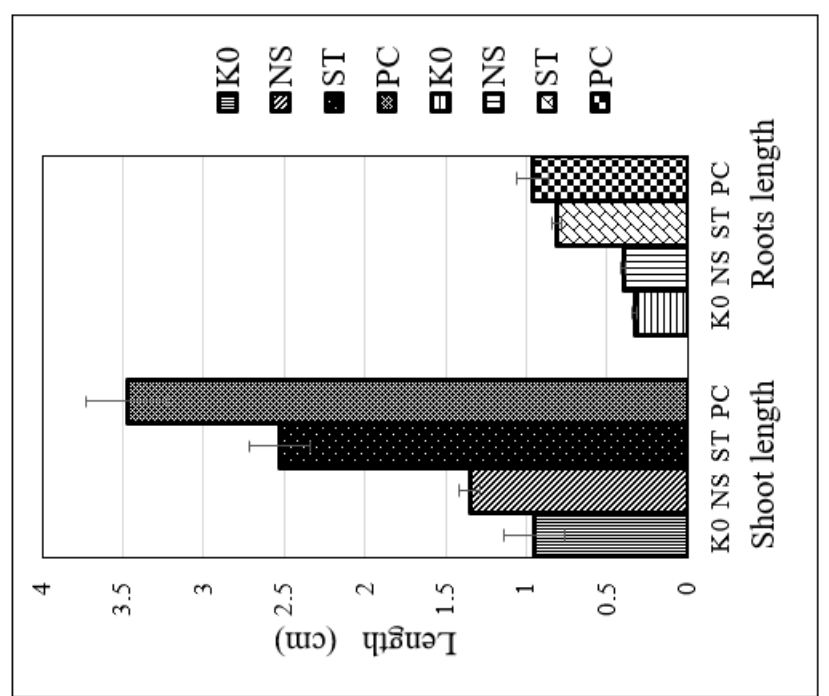

0
0
0
0
0
ज.
0
0
0
के

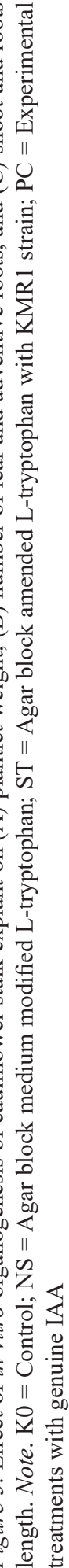
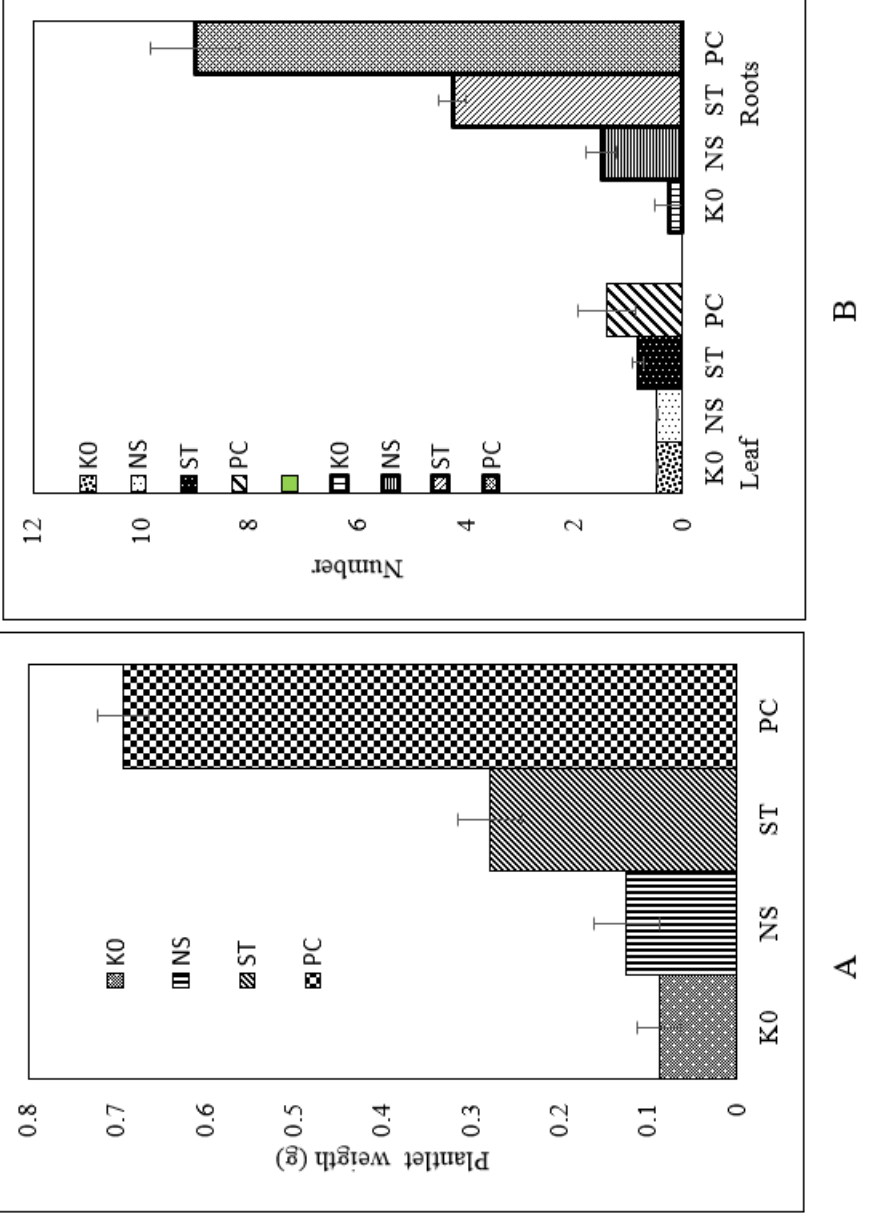

을 


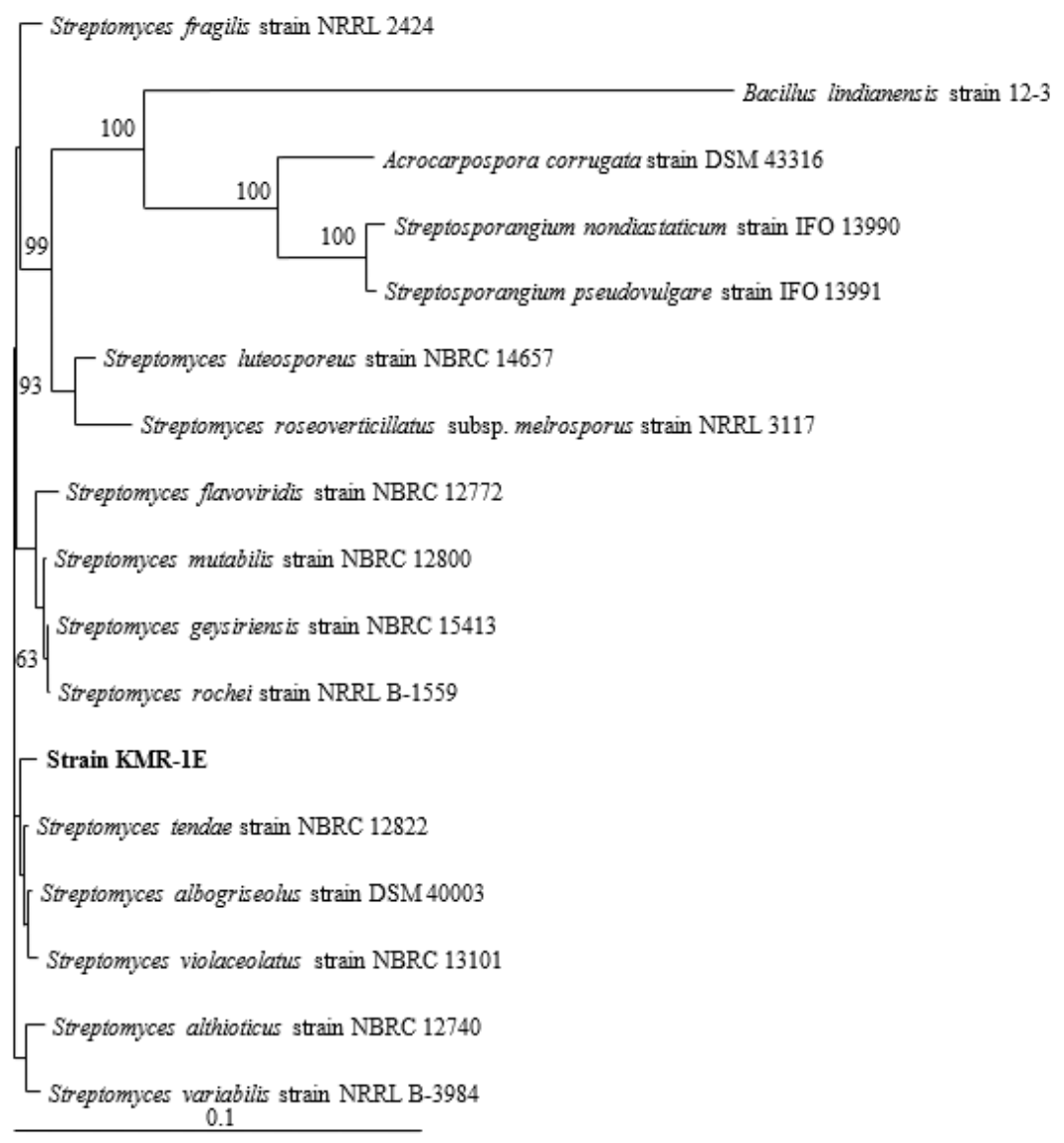

Figure 6. Neighbor-joining phylogenetic tree inferred from 16S rRNA gene sequences. This shows the relationship between endophytic bacteria KMR-1E strain and related genera. The bootstrap values were further expressed as percentages of 1,000 replications, and those $\geq 50 \%$ are expressed at branch points. Furthermore, the score bar denotes 1 nucleotide substitution per 100 nucleotides

\section{CONCLUSION}

Fifteen (15) isolates of actinomycetes recovered from plant tissue could provide interesting sources of endophytic strains producing indole-3-acetic acid. The work demonstrates the potential of strains Streptomyces sp. KMR-1E showed the indole-3-acetic acid produced by endophytic actinomycetes isolates of Cinnamomun sp. plant. The strain has the potential to promote seedling germination as well as induce shoot and root in vitro organogenesis in cauliflower stalk explant.

\section{ACKNOWLEDGEMENTS}

The authors appreciate the Ministry of Higher Education, Indonesia, for the financial support provided under grant PNBP PGB Universitas Negeri Makassar. No: 4713/UN36/KP/2019. 


\section{CONFLICT OF INTEREST}

The authors declare no conflict of interest regarding the publication of this article.

\section{REFERENCES}

Ahmad, F., Ahmad, I., \& Khan, M. S. (2005). Indole acetic acid production by the indigenous isolates of Azotobacter and fluorescent Pseudomonas in the presence and absence of tryptophan. Turkish Journal of Biology, 29, 29-34.

Ali, A., Junda, M., Karim, H., \& Nuryani, S. (2017). Characterization and in vitro antifungal assay against Fusarium oxysporum f. sp. passiflora of endophytic actinomycetes from purple passion fruit plants of South Sulawesi, Indonesia. Asian Journal of Microbiology, Biotechnology and Environmental Sciences, 19(2), 105-114.

Andreote, F. D., de Araújo, W. L., de Azevedo, J. L., van Elsas, J. D., da Rocha, U. N., \& van Overbeek, J. S. (2009). Endophytic colonization of potato (Solanum tuberosum L.) by a novel competent bacterial endophyte, Pseudomonas putida strain P9, and its effect on associated bacterial communities. Applied and Environmental Microbiology, 75(11), 3396-3406. https://doi. org/10.1128/aem.00491-09

Badji, B., Zitouni, A., Mathieu, F., Lebrihi, A., \& Sabaou, N. (2006). Antimicrobial compounds produced by Actinomadura sp. AC104 isolated from an Algerian Sahara soil. Canadian Journal of Microbiology, 52(4), 373-382. https://doi. org/10.1139/w05-132

Bano, N., \& Musarrat, J. (2003). Characterization of a new Pseudomonas aeruginosa strain NJ15 as a potential biocontrol agent. Current Microbiology, 46(5), 324-328. https://doi. org/10.1007/s00284-002-3857-8

Berg, G. (2009). Plant-microbe interactions promoting plant growth and health: Perspectives for controlled use of microorganisms in agriculture. Applied Microbiology and Biotechnology, 84(1),
11-18. https://doi.org/10.1007/s00253-0092092-7

Cao, L., Qiu, Z., You, J., Tan, H., \& Zhou, S. (2004). Isolation and characterization of endophytic Streptomyces strains from surface-sterilized tomato (Lycopersicon esculentum) roots. Letters in Applied Microbiology, 39(5), 425-430. https:// doi.org/10.1111/j.1472-765x.2004.01606.x

da Costa, P. B., Granada, C. E., Ambrosini, A., Moreira, F., Souza, R., Passos, J. F. M., Arruda, L., \& Passaglia, L. M. P. (2014). A model to explain plant growth promotion traits: A multivariate analysis of 2,211 bacterial isolates. PLOS One, 9(12), e116020. https://doi. org/10.1371\%2Fjournal.pone.0116020

Datta, C., \& Basu, P. S. (2000). Indole acetic acid production by a Rhizobium species from root nodules of a leguminous shrub, Cajanus cajan. Microbiological Research, 155(2), 123-127. https://doi.org/10.1016/s0944-5013(00)80047-6

de Araújo, J. M., Silva, A. C., \& Azevedo, J. L. (2000). Isolation of endophytic actinomycetes from roots and leaves of maize (Zea mays L.). Brazilian Archives of Biology and Technology, 43(4), 447-451. https://doi.org/10.1590/S151689132000000400016

Debananda, S., Ningthoujam, S. S. K., \& Tamreihao, N. S. (2009). Antagonistic activities of local actinomycetes isolates against rice fungal pathogens. African Journal of Microbiology Research, 3(11), 737- 742.

Dochhil, H., Dkhar, M. S., \& Barman, D. (2013). Seed germination enhancing activity of endophytic Streptomyces isolated from indigenous ethnomedicinal plant Centella asiatica. International Journal of Pharma and Bio Sciences, 4(1), 256-262.

El-Tarabily, K. A. (2008). Promotion of tomato (Lycopersicon esculentum Mill.) plant growth by rhizosphere competent 1-aminocyclopropane1 -carboxylic acid deaminase-producing 
streptomycete actinomycetes. Plant and Soil, 308(1), 161-174. https://doi.org/10.1007/s11104008-9616-2

Felsenstein, J. (1985). Confidence limits of phylogenies: an approach using the bootstrap. Evolution, 39(4), 783-791. https://doi. org/10.2307/2408678

Goudjal, Y., Toumatia, O., Sabaou., Barakate, M., Mathieu, F., \& Zitouni, A. (2013). Endophytic actinomycetes from spontaneous plants of Algerian Sahara: Indole-3-acetic acid production and tomato plants growth promoting activity. World Journal of Microbiology and Biotechnology, 29(10), 1821-1829. https://doi. org/10.1007/s11274-013-1344-y

Hoque, M. E. (2010). In vitro tuberization in potato (Solanum tuberosum L.). Plant Omics Journal, 3(1), 7-11.

Idris, E. E., Iglesias, D. J., Talon, M., \& Borriss, R. (2007). Tryptophan-dependent production of indole-3-acetic acid (IAA) affects level of plant growth promotion by Bacillus amyloliquefaciens FZB42. Molecular Plant Microbe Interactions, 20(6), 619-626. https://doi.org/10.1094/mpmi20-6-0619

Ilic, S. B., Konstantinovic, S. S., Todorovic, Z. B., Lazic, M. L., Veljkovic, V. B., Jokovic, N., \& Radovanovic, B. C. (2007). Characterization and antimicrobial activity of the bioactive metabolites in streptomycete isolates. Microbiology, 76(4), 421-428. https://doi. org/10.1134/S0026261707040066

Jasim, B., Joseph, A. A., John, C. J., Mathew, J., \& Radhakrishnan, E. K. (2014). Isolation and characterization of plant growth promoting endophytic bacteria from the rhizome of Zingiber officinale. 3 Biotech, 4(2), 197-204. https://doi. org/10.1007/s13205-013-0143-3

Jog, R., Pandya, M., Nareshkumar, G., \& Rajkumar, S. (2014). Mechanism of phosphate solubilization and antifungal activity of Streptomyces spp. isolated from wheat roots and rhizosphere and their application in improving plant growth. Microbiology, 160(4), 778-788. https://doi. org/10.1099/mic.0.074146-0

Kaur, N. D., Vyvadilova, M., Klima, M., \& Bechyne, M. (2006). A simple procedure for mesophyll protoplast culture and plant regeneration in Brassica oleracea L. and Brassica napus L.. Czech Journal of Genetics and Plant Breeding, 42(3), 103-110. http://doi.org/10.17221/3649CJGPB

Kerlley, C. D., Flavia, D. P., Paula, S. A., Fabiano, G. S., Jose, W. S., \& Carlos, C. E. (2012). In vitro cultivation of Anacardium othonianum Rizz.: Effect of growth regulator, explants orientation and lighting. African Journal of Biotechnology, 11(7), 1559-1565. https://doi.org/10.5897/ AJB10.1383

Khamna, S., Yokota, A., Peberdy, J. F., \& Lumyong, S. (2010). Indole-3-acetic acid production by Streptomyces sp. isolated from some Thai medicinal plant rhizosphere soils. Eurasian Journal of Biosciences, 4(1), 23-32. https://doi. org/10.5053/ejobios.2010.4.0.4

Maela, P. M., \& Serepa-Dlamini, M. H. (2019). Current understanding of bacterial endophytes, their diversity, colonization and their roles in promoting plant growth. Applied Microbiology, 5(1), 1-12.

Malus'a, E., Sas-Paszt, L., \& Ciesielska, J. (2012). Technologies for beneficial microorganisms inocula used as biofertilizers. The Scientific World Journal, 2012, 491206. https://dx.doi. org/10.1100\%2F2012\%2F491206

Nair, D. N., \& Padmavathy, S. (2014). Impact of endophytic microorganisms on plants, environment and humans. The Scientific World Journal, 2014, 250693. https://doi. org/10.1155/2014/250693

Ovesna, J., Ptacek, L., \& Opatrany, Z. (1993). Factor influencing the regeneration capacity of 
oilseed rape and cauliflower in transformation experiments. Biologia Plantarum, 35(1), 107112. https://doi.org/10.1007/BF02921131

Saitou, N., \& Nei, M. (1987). The neighbor-joining method: A new method for reconstructing phylogenetic trees. Molecular Biology and Evolution, 4(4), 406-426. https://doi.org/10.1093/ oxfordjournals.molbev.a040454

Sardi, P., Saracchi, M., Quaroni, S., Petrolini, B., Borgonovi, G. E., \& Merli, S. (1992). Isolation of endophytic Streptomyces strains from surfacesterilized roots. Applied and Environmental Microbiology, 58(8), 2691-2693. https://doi. org/10.1128/AEM.58.8.2691-2693.1992

Sharma, S. B., Sayyed, R. Z., Trivedi, M. H., \& Gobi, T. A. (2013). Phosphate solubilizing microbes: Sustainable approach for managing phosphorus deficiency in agricultural soils. SpringerPlus, 2(1), 587. https://doi.org/10.1186/2193-1801$2-587$

Shi, Y., Lou, K., \& Li, C. (2009). Promotion of plant growth by phytohormone-producing endophytic microbes of sugar beet. Biology and Fertility of Soils, 45(6), 645-653. https://doi.org/10.1007/ s00374-009-0376-9

Shutsrirung, A., Chromkaew, Y., Pathom-Aree, W., Choonluchanon, S., \& Boonkerd, N. (2014). Diversity of endophytic actinomycetes in mandarin grown in northern Thailand, their phytohormone production potential and plant growth promoting activity. Soil Science and Plant Nutrition, 59(3), 322-330. https://doi.org/ 10.1080/00380768.2013.776935

Solans, M., Vobis, G., Cass'an, F., Luna, V., \& Wall, L. G. (2011). Production of phytohormones by root-associated saprophytic actinomycetes isolated from the actinorhizal plant Ochetophila trinervis. World Journal of Microbiology and Biotechnology, 27(9), 2195-2202. https://doi. org/10.1007/s11274-011-0685-7
Suzuki, S., Yamamoto, K., Okuda, T., Nishio, M., Nakanishi, N., \& Komatsubara, S. (2000). Selective isolation and distribution of Actinomadura rugatobispora strains in soil. Actinomycetologica, 14(2), 27-23. http://doi. org/10.3209/saj.14_27

Thompson, J. D., Higgins, D. G., \& Gibson, T. J. (1994). CLUSTAL W: Improving the sensitivity of progressive multiple sequence alignment through sequence weighting, position-specific gap penalties and weight matrix choice. Nucleic Acids Research, 22(22), 4673-4680. https://doi. org/10.1093/nar/22.22.4673

Tokala, R. K., Strap, J. L., Jung, C. M., Crawford, D. L., Salove, M. H., Deobald, L. A., Bailey, J. F., \& Morra. M. J. (2002). Novel plant microbe rhizosphere interaction involving Streptomyces lydicus WYEC108 and the pea plant (Pisum sativum). Applied and Environmental Microbiology, 68(5), 2161-2171. https://doi. org/10.1128/aem.68.5.2161-2171.2002

Vaghasiat, H. L., Patel, G. M., Chudasama, R. S., \& Bhott, K. R. (2011). Screening of IAA from rhizosphere microflora of field crops. Bioscience Discovery, 2(1), 94-100.

Vikram, P. (2011). Production of indole acetic acid by Azotobacter sp.. Recent Research in Science and Technology, 3(12), 14-16.

Whitman, W., Goodfellow, M., Kampfer, P., Busse, H. J., Trujilo, M., Ludwig, W., Suzuki, K., \& Parte, A. (Eds.) (2012). Bergey's manual ${ }^{\circledR}$ of systematic bacteriology: The Actinobacteria, Part $A$ and $B$ ( $2^{\text {nd }}$ ed., Vol. 5). Springer. https:// doi.org/10.1007/978-0-387-68233-4

Zhao, L., Xu, Y., \& Lai, X. (2018). Antagonistic endophytic bacteria associated with nodules of soybean (Glycine max L.) and plant growthpromoting properties. Brazilian Journal of Microbiology, 49(2), 269-278. https://doi. org/10.1016/j.bjm.2017.06.007 